\title{
Study on Crystal Structure and Thermal Behavior of Sodium Tetrazolate and Sodium 5-Chlorotetrazolate
}

\author{
WANG Xiaojun 1, a , LIU Jiping ${ }^{1, b^{*}}$, BI Xiaolu ${ }^{1, ~ c}$, LI Hongcheng ${ }^{1, d}$, ZHAO Wei $^{1, ~ e}$, \\ WANG Dong ${ }^{1, f}$ \\ ${ }^{1}$ Beijing Institute of Technology, Beijing 100081, China \\ a20909055@bit.edu.cn, bliujp@bit.edu.cn
}

\begin{abstract}
Keywords: Energetic material, Coordination complex, Sodium 5-Chlorotetrazolate, Crystal structure, Kinetic parameter

Abstract. Sodium tetrazolate and sodium 5-chlorotetrazolate crystals obtained by recrystallization centred on sodium ion, and the sodium ion was coordinated by tetrazolate rings and crystal water; the packing arrangements of sodium tetrazolate and sodium 5-chlorotetrazolate were rhombus structure which lead to highest thermostability and intersecting channel structure viewed along $b$ axis, respectively; there was a gap between molecules and larger space viewed along $a$ axis of sodium 5-chlorotetrazolate crystal drawing which can coordinate with nitrogen-rich groups and metal ion. The results of thermodynamics calculation indicated that the activation energy of sodium tetrazolate was about $200 \mathrm{~kJ} \cdot \mathrm{mol}^{-1}$, sodium 5-chlorotetrazolate was $260-270 \mathrm{~kJ} \cdot \mathrm{mol}^{-1}$ which was higher than sodium tetrazolate, however, the decomposition temperature of sodium 5 -chlorotetrazolate $\left(241{ }^{\circ} \mathrm{C}\right)$ was lower than sodium tetrazolate $\left(320^{\circ} \mathrm{C}\right)$ which can be explained that the pre-exponential factor $(\lg \mathrm{A})$ of sodium 5-chlorotetrazolate (27.8) was greater than that of sodium tetrazolate (18.2), in other words, sodium 5-chlorotetrazolate had more active sites.
\end{abstract}

\section{Introduction}

Tetrazole derivative is a kind of nitrogen-rich heterocyclic compound containing unsaturated five membered ring. It has flat structure, high nitrogen content and many $\mathrm{N}-\mathrm{N}, \mathrm{C}-\mathrm{N}, \mathrm{N}=\mathrm{N}, \mathrm{C}=\mathrm{N}$ bonds, possessing aromaticity, high formation enthalpy, high density, low sensitivity, good thermal stability and other characteristics; the final product after combustion or explosion is nitrogen gas with low smoke that has no pollution and be environmentally friendly. Thus, tetrazole derivative is an ideal high energy density materials (HEDMs) ${ }^{[1,2]}$. Besides, its chemical property is very active, a great varieties of derivatives can be obtained by deprotonation, protonation, substitution, corrdination reactions ${ }^{[3-11]}$ which are widely used in biomedicine, agriculture, energetic materials, gas generating agent and microelectronics fields.

At present, coordination complexs or metal salts of tetrazoe derivatives have excellent explosion properties and are widely used as initiating explosive of blasting equipment and energetic catalyst. It becomes an important research of energrtic materials and be a hot spot of the scientists all over the world $^{[12-17]}$.

This article analyzed the crystal structure of sodium tetrazole and sodium 5-chlorotetrazolate, studied the thermal decomposition behavior of the two crystals and calculated thermal dynamic parameters (activation energy and pre-exponential factor) using Kissinger and Flynn-Wall-Ozawa equations for the first time, discussed the effect of crystal structure and thermal dynamic parameters on the thermal stability, which has important academic values.

\section{Experimental}

Synthesis of sodium tetrazolate. $0.01 \mathrm{~mol}(0.7 \mathrm{~g}) 1 \mathrm{H}$-tetrazole and $15 \mathrm{~mL}$ distilled water were added to a $50 \mathrm{~mL}$ round-bottom flask (the $\mathrm{pH}$ of the solution was about 3$)$, then to the solution, $0.01 \mathrm{~mol}(0.4$ g) sodium hydroxide solution was dropwise added with stirring at ambient temperature for $1 \mathrm{~h}$ (this moment the $\mathrm{pH}$ of the solution was about 7). The reaction solvent was removed using a rotary evaporator; A white solid matter was dried by distillation of azeotrope with three $20 \mathrm{~mL}$ portions of 
ethyl alcohol and recrystallized from hot ethyl alcohol. The colorless crystalline solid of sodium tetrazolate was obtained; yield: $1.04 \mathrm{~g}(94.5 \%)$; m.p. $275.97{ }^{\circ} \mathrm{C} ;{ }^{1} \mathrm{H}$ NMR $\left(\mathrm{d}_{6}\right.$-DMSO, 400MHz) $\delta$ : $8.10(\mathrm{~s}, 1 \mathrm{H}) ;{ }^{13} \mathrm{C}$ NMR $\left(\mathrm{d}_{6}\right.$-DMSO, 400MHz) $\delta: 148.41(\mathrm{~s}, \mathrm{C})$; IR (KBr) v: 3158.51, 3057.05, 1658.26, 1524.31, 1401.98, 1256.77, 1145.02, $937.83 \mathrm{~cm}^{-1}$; ESI-MS m/z (\%): 69.2 [M]', 41.0 [M-N $]^{-}$; Anal. Calcd for $\mathrm{CH}_{3} \mathrm{~N}_{4} \mathrm{NaO}$ : C 10.91, H 2.75, N 50.92; found C 10.20, H 3.46; N 51.43.

Synthesis of sodium 5-chlorotetrazolate. $0.01 \mathrm{~mol}(0.7 \mathrm{~g}) 1 \mathrm{H}$-tetrazole and $0.12 \mathrm{~mol}$ acetic acid solution (the concentration was $50 \%$ ) were added to a $100 \mathrm{~mL}$ round-bottom flask, then to the solution, $0.12 \mathrm{~mol}$ sodium hypochlorite solution was dropwise added with stirring at $55^{\circ} \mathrm{C}$ for $6 \mathrm{~h}$. All of the reaction solvents were removed using a rotary evaporator; the solid matter was dried by distillation of azeotrope with three $20-\mathrm{mL}$ portions of ethyl alcohol and extracted with acetone; after filtering the $\mathrm{NaCl}$, the filtrate was dried over $\mathrm{MgSO}_{4}$. Following the removal of acetone by purging with warm air, sodium 5-chlorotetrazolate dihydrate was obtained as a colorless crystal with a $92.76 \%$ yield $(1.3496 \mathrm{~g}) ;{ }^{13} \mathrm{C}$ NMR $\left(\mathrm{d}_{6}-\mathrm{DMSO}, 400 \mathrm{MHz}\right) \delta: 150.34(\mathrm{~s}, \mathrm{C})$; IR $(\mathrm{KBr})$ v: 3512.89 , 1628.05, 1376.12, 1354.65, 1195.19, $724.49 \mathrm{~cm}^{-1}$; ESI-MS m/z (\%): $102.8[\mathrm{M}]^{-}\left({ }^{35} \mathrm{Cl}\right), 104.8[\mathrm{M}]^{-}$ $\left({ }^{37} \mathrm{Cl}\right), 75\left[\mathrm{M}-\mathrm{N}_{2}\right]^{-}\left({ }^{35} \mathrm{Cl}\right), 76.8\left[\mathrm{M}-\mathrm{N}_{2}\right]^{-}\left({ }^{37} \mathrm{Cl}\right), 42\left[\mathrm{M}-\mathrm{N}_{2}-\mathrm{Cl}+2 \mathrm{H}\right]^{-}$; Anal. Calcd for $\mathrm{CH}_{4} \mathrm{ClN}_{4} \mathrm{NaO}_{2}: \mathrm{C}$ 7.39, H 2.48, N 34.48; found C 7.30, H 2.44; N 34.32 .

\section{Results and discussion}

Crystal structure. The crystal structure parameter and diffraction data of sodium tetrazole and sodium 5-chlorotetrazolate were collected by Bruker SMART 1000 CCD and were shown in Table 1. The molecular structures and the crystal packing structures viewed along coordinate axis were shown in Fig 1-3, respectively.

Table 1 Crystallographic data of sodium tetrazolate and sodium 5-chlorotetrazolate ${ }^{[18]}$

\begin{tabular}{|c|c|c|}
\hline Compounds & Sodium tetrazolate & Sodium 5-chlorotetrazolate \\
\hline Formula & $\mathrm{CH}_{3} \mathrm{~N}_{4} \mathrm{NaO}$ & $\mathrm{C}_{0.5} \mathrm{H}_{2} \mathrm{Cl}_{0.5} \mathrm{~N}_{2} \mathrm{Na}_{0.5} \mathrm{O}$ \\
\hline Crystal system & Orthorhombic & Orthorhombic \\
\hline Space group & Pmc2 (1) & Pnma \\
\hline Temperature (K) & $153(2) \mathrm{K}$ & 293(2) K \\
\hline Wavelength $(\AA)$ & 0.71073 & 0.71073 \\
\hline$a(\AA)$ & $5.847(4)$ & $6.8611(19)$ \\
\hline$b(\AA)$ & $5.605(3)$ & $6.9243(19)$ \\
\hline$c(\AA)$ & $6.387(4)$ & $12.281(4)$ \\
\hline Volume $\left(\AA^{3}\right)$ & 209.3(2) & $583.5(3)$ \\
\hline Z & 2 & 8 \\
\hline $\mathrm{D}_{\mathrm{c}}\left(\mathrm{Mg} \cdot \mathrm{m}^{-3}\right)$ & 1.746 & 1.850 \\
\hline Crystal size $(\mathrm{mm})$ & $0.67 \times 0.20 \times 0.08$ & $0.48 \times 0.35 \times 0.28$ \\
\hline$\theta$ range & $3.48^{\circ}$ to $31.52^{\circ}$ & $3.32^{\circ}$ to $31.52^{\circ}$ \\
\hline Dataset & $-8: 8,-8: 7,-9: 9$ & $-9: 10,-10: 10,-17: 18$ \\
\hline $\mathrm{R}$ indices (all data) & $R_{1}=0.0328, \mathrm{w} R_{2}=0.0666$ & $R_{1}=0.0283, \mathrm{w} R_{2}=0.0780$ \\
\hline $\mathrm{CCDC}$ & 1028253 & 1028254 \\
\hline & & \\
\hline
\end{tabular}

Fig. 1 Molecular structures of sodium tetrazolate (left) and sodium 5-chlorotetrazolate (right) 

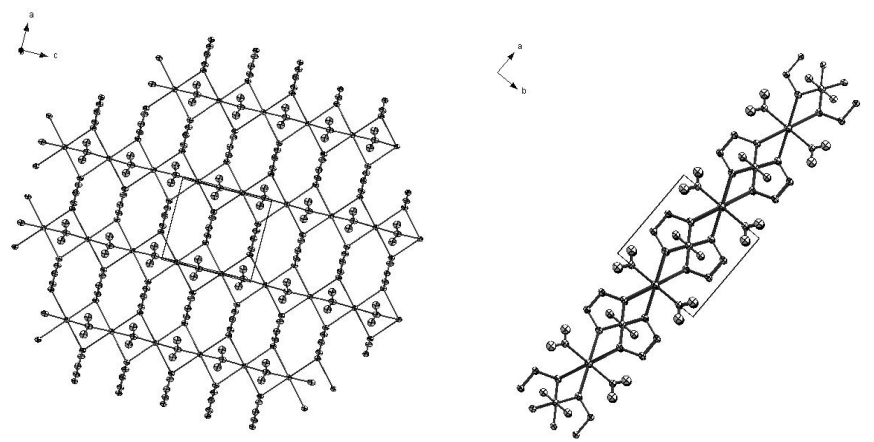

Fig. 2 Viewed along $b$ (left) and $c$ (right) axis in the crystal packing structure of sodium tetrazolate
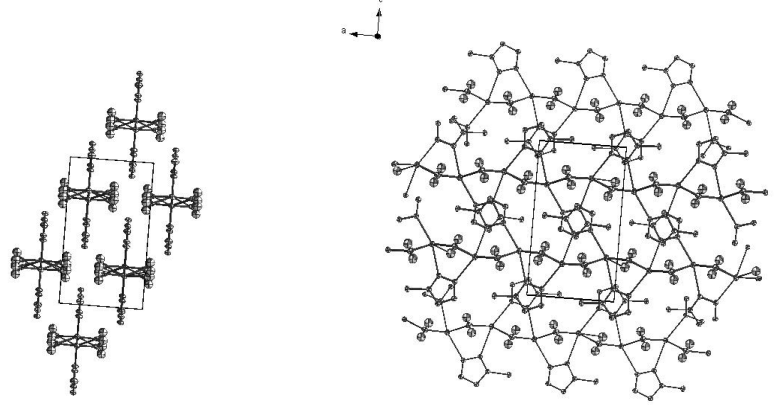

Fig. 3 Viewed along $a$ (left) and $b$ (right) axis in the crystal packing structure of sodium 5-chlorotetrazolate

From the Table 1, sodium tetrazolate crystallizes in the orthorhombic space group Pmc2(1) with a cell volume of $209.3(2) \AA^{3}$, density of $1.746 \mathrm{Mg} \cdot \mathrm{m}^{-3}$; sodium 5 -chlorotetrazolate crystallizes in the orthorhombic space group Pnma with a cell volume of $583.5(3) \AA^{3}$, density of $1.850 \mathrm{Mg} \cdot \mathrm{m}^{-3}$. Fig. 1 showed that the two crystals were composed of $\mathrm{Na}^{+}$central metal ion, tetrazole ring ligand and crystal water, and the $\mathrm{Na}^{+}$of sodium tetrazolate linked four tetrazole rings and two water molecules, while the $\mathrm{Na}^{+}$of sodium 5-chlorotetrazolat linked two tetrazole rings and four water molecules. Viewed along $b$ axis, the crystal packing structure of sodium tetrazolate was rhombus and it was long-chain viewed along $c$ axis (Fig. 2); the crystal packing structure of sodium 5-chlorotetrazolate was intersecting channel viewed along $b$ axis, and it existed gap between intermolecular that offered space for coordination of metal salt and other groups viewed along $a$ axis(Fig. 3). Compared with the intersecting channel structure of sodium 5-chlorotetrazolate, the rhombus structure of sodium tetrazolate was more stable.

Thermal behavior and stability. The thermal behaviors of sodium 5-chlorotetrazolate dihydrate and sodium tetrazolate monohydrate were investigated by TG/DSC at a heating rate of $10{ }^{\circ} \mathrm{C} \mathrm{min}{ }^{-1}$ in the temperature range from $35-450{ }^{\circ} \mathrm{C}$ with an amount of $1.6088 \mathrm{mg}$ and $3.4073 \mathrm{mg}$, respectively. Fig. 4 showed the TG/DSC curves of sodium tetrazolate and sodium 5-chlorotetrazolate.
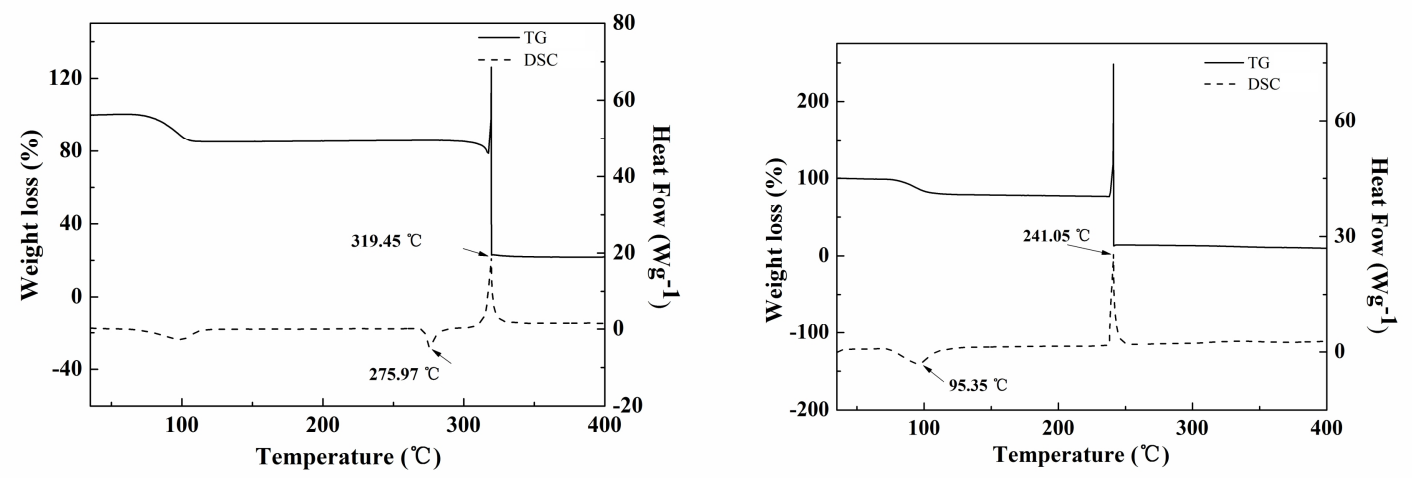

Fig. 4 TG/DSC of sodium tetrazolate (left) and sodium 5-chlorotetrazolate (right) at a heating rate of $10^{\circ} \mathrm{C} \cdot \mathrm{min}^{-1}$ 
The results of Fig. 4 indicated that the TG curves of the two compounds all had two phase of weightlessness, the first weight loss stage was caused by the evaporation of crystal water at about $100{ }^{\circ} \mathrm{C}$; from the DSC curves, sodium tetrazolate and sodium 5-chlorotetrazolate showed endothermic peak and the decomposition temperatures were $320^{\circ} \mathrm{C}$ and $241{ }^{\circ} \mathrm{C}$, respectively; the TG curves appeared overweight which was caused by the rapid decomposition and the release of nitrogen gas. In addition, there was a melting phenomenon at the temperature of $276{ }^{\circ} \mathrm{C}$ in the thermal analysis of sodium tetrazolate, and sodium 5-chlorotetrazolate didn't.

Thermodynamics. Testing the thermogravimetry and differential thermal gravity (TG/DTG) curves of the two compounds at a heating rate of $2.5,5,10,20{ }^{\circ} \mathrm{C} \cdot \mathrm{min}^{-1}$ in the temperature range from $35-400{ }^{\circ} \mathrm{C}$ under a nitrogen flow of $20 \mathrm{~mL} \cdot \mathrm{min}^{-1}$; using the obtained heating rate $\beta$ and corresponding thermal decomposition peak $\mathrm{T}_{\mathrm{p}}$, the thermodynamic parameter (i.e. activation energy and pre-exponential factor) was calculated by Kissinger and Flynn-Wall-Ozawa (FWO) methods, respectively.

The Kissinger and FWO equations were:

$$
\begin{aligned}
& \ln \left(\frac{\beta}{T_{p}^{2}}\right)=\ln \left(\frac{A R}{E}\right)-\frac{E_{K}}{R T_{p}} \\
& \lg \beta=\lg \left(\frac{A E}{R G(\alpha)}\right)-2.305-0.4567 \frac{E_{O}}{R T}
\end{aligned}
$$

Where $\beta=$ heating rate $\left[\mathrm{K} \cdot \mathrm{min}^{-1}\right], \mathrm{A}=$ pre-exponential factor $\left[\mathrm{min}^{-1}\right], \mathrm{R}=$ gas constant $(=8.314$ $\left.\mathrm{J} \cdot \mathrm{K}^{-1} \cdot \mathrm{mol}^{-1}\right), \mathrm{E}=$ activation energy $\left[\mathrm{kJ} \cdot \mathrm{mol}^{-1}\right]\left(\mathrm{E}_{\mathrm{K}}\right.$ and $\mathrm{E}_{\mathrm{O}}$ are calculated by Kissinger and $\mathrm{FWO}$, respectively), $\mathrm{T}=$ absolute temperature $[\mathrm{K}], \mathrm{G}(\alpha)=$ integral function describing decomposition reaction.

Table 2 showed the kinetic data of the two compounds in different heating rate. The activation energy and pre-exponential factor (Table 3) was calculated by the linear fitting curves (Fig. 5).

Table 2 The kinetics data of sodium tetrazolate and sodium 5-chlorotetrazolate under different heating rate

\begin{tabular}{cccccc}
\hline Compounds & $\begin{array}{c}\beta \\
\left(\mathrm{K} \cdot \mathrm{min}^{-1}\right)\end{array}$ & $\begin{array}{c}\mathrm{T}_{\mathrm{p}} \\
(\mathrm{K})\end{array}$ & $\begin{array}{c}1 / \mathrm{T}_{\mathrm{p}} \\
\left(1 \times 10^{-3} \mathrm{~K}^{-1}\right)\end{array}$ & $\begin{array}{c}\text { Kissinger } \\
\ln \left(\beta / \mathrm{T}_{\mathrm{P}}^{2}\right) /\left(\mathrm{K}^{-1} \cdot \mathrm{min}^{-1}\right)\end{array}$ & $\begin{array}{c}\mathrm{FWO} \\
\lg \beta /\left(\mathrm{K}^{-1} \cdot \min ^{-1}\right)\end{array}$ \\
\hline \multirow{3}{*}{ Sodium } & 2.5 & 576.07 & 1.73590 & -11.7961676 & 0.397940 \\
tetrazolate & 5 & 585.23 & 1.70873 & -11.1345720 & 0.698970 \\
& 10 & 595.82 & 1.67836 & -10.4772921 & 1.000000 \\
& 20 & 602.82 & 1.65887 & -9.8075050 & 1.301030 \\
\hline \multirow{3}{*}{ Sodium } & 2.5 & 515.32 & 1.94054 & -9.2665779 & 0.397940 \\
5-chlorotetrazolate & 5 & 506.40 & 1.97472 & -10.8452158 & 0.698970 \\
& 10 & 512.15 & 1.95255 & -10.1746500 & 1.000000 \\
& 20 & 517.15 & 1.93367 & -9.5009337 & 1.301030 \\
\hline
\end{tabular}
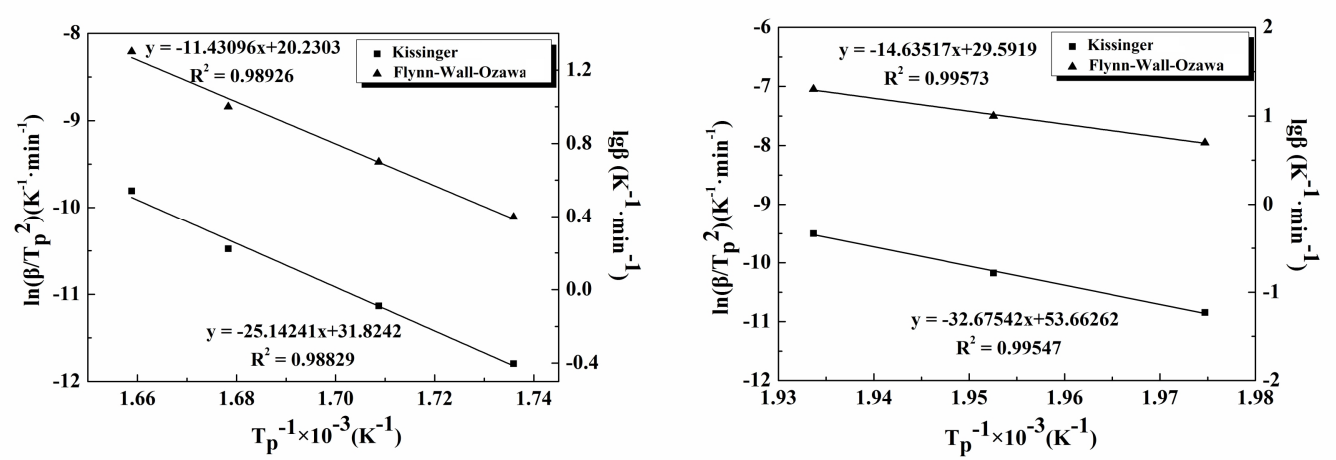

Fig. 5 The linear fitting curves of Kinssinger and FWO for sodium tetrazolate and sodium 5-chlorotetrazolate(the TG/DTG data was unsatisfied at the heating rate of $2.5^{\circ} \mathrm{C} \cdot \mathrm{min}^{-1}$ ) 
Table 3 Kinetic parameter of the two compounds

\begin{tabular}{cccccc}
\hline Compounds & $\begin{array}{c}\text { Activation } \\
\text { energy } \\
\mathrm{E}_{\mathrm{K}}\left(\mathrm{kJ} \cdot \mathrm{mol}^{-1}\right)\end{array}$ & $\begin{array}{c}\text { Llinear } \\
\text { correlation } \\
\text { coefficient } \mathrm{R}_{\mathrm{K}}{ }^{2}\end{array}$ & $\lg _{\mathrm{K}}$ & $\begin{array}{c}\text { Activation } \\
\text { energy } \\
\mathrm{E}_{\mathrm{O}}(\mathrm{kJ} \cdot \mathrm{mol}-1)\end{array}$ & $\begin{array}{c}\text { Llinear } \\
\text { correlation } \\
\text { coefficient } \mathrm{R}_{\mathrm{O}}{ }^{2}\end{array}$ \\
\hline $\begin{array}{c}\text { Sodium tetrazolate } \\
\text { Sodium }\end{array}$ & 209.03 & 0.98829 & 18.2 & 208.10 & 0.98926 \\
5-chlorotetrazolate & 271.66 & 0.99547 & 27.8 & 266.43 & 0.99573 \\
\hline
\end{tabular}

The results showed that the values of kinetic parameter were reliable and valuable because the linear correlation coefficient $R^{2}$ was close to one and the data relevancy was higher; the values of $E_{K}$ and $E_{O}$ were similar that indicated the thermal decomposition kinetic method was reasonable; the larger the activation energy is, the greater the energy of decomposition need, and that is to say the higher the decomposition temperature is, the $\mathrm{E}_{\mathrm{K}}$ of sodium 5-chlorotetrazolate (271.66) was higher than sodium tetrazolate (209.03), however, the pre-exponential factor $\lg \mathrm{A}$ of sodium 5-chlorotetrazolate (27.8) was greater than that of sodium tetrazolate (18.2), in other words, having more active sites. So, the decomposition temperature of sodium 5-chlorotetrazolate was lower than sodium tetrazolate.

\section{Conclusions}

This article in-depth studied the crystal structures, thermal decomposition behavior and thermal dynamic of sodium tetrazolate and sodium 5-chlorotetrazolate. From the crystal packing axial dierction figures, we got the results: the rhombus structure of sodium tetrazolate was more stable than the intersecting channel sturcture of sodium 5-chlorotetrazolate, and it existed gap between the crystal moleculas of sodium 5-chlorotetrazolate, providing enough space for the coordination with rich nitrogen groups and metal ion. The TG/DSC curves of the two crystals proved the decomposition temperature of sodium tetrazolate was significantly higher than sodium 5-chlorotetrazolate, and sodium 5-chlorotetrazolate had no melting point which indicated that its structure was easy to fracture; the activation energy and pre-exponential factor were calculated by using non-isothermal kinetic equation (Kissinger and FWO method) that demonstrated the activation energy values got by using Kissinger and FWO methods were similar and had reference value, in addition, the pre-exponential factor of sodium 5-chlorotetrazolate being higher than that of sodium tetrazolate indicated that sodium 5-chlorotetrazolate had more reactive stes, so the decompostion temperature of sodium 5-chlorotetrazolate was lower than that of sodium tetrazolate despite having higher activation energy.

\section{References}

[1] C.Ye, J. C. Xiao, B. Twamley, et al. Energetic salts of azotetrazolate, iminobis (5-tetrazolate) and 5, 5'-bis (tetrazolate), Chem. Commun, 21 (2005) 2750-2752.

[2] X. J. Liu, H. J. Zhang, Q. H. Lin, et al. Progress of Study on the Synthesis of Azole Energetic Ionic Compounds, Chinese Journal of Explosives \& Propellants, 33(2010), 6-10.

[3] A. R. Katritzky, S. Singh, K. Kirichenko, et al. In search of ionic liquids incorporating azolate anions, Chem. Eur. J., 12(2006), 4630-4641.

[4] T. M. Klapötke, J. Stierstorfer. Azidoformamidinium and 5-aminotetrazolium dinitramide-two highly energetic isomers with a balanced oxygen content, Dalton T., (2009), 643-653.

[5] F. R. Benson, The chemistry of the tetrazoles, Chem. Rev., 41(1947), 1-61.

[6] I. Gronde, N. W. Mitzel. Silylated Tetrazoles and Triazoles, Z. Anorg. Allg. Chem., 635(2009), 1313-1320.

[7] T. Wu, B. H. Yi, D. Li. Two novel nanoporous supramolecular architectures based on copper (I) coordination polymers with uniform $(8,3)$ and $(8210)$ nets: in situ formation of tetrazolate ligands, 
Inorg. Chem., 44(2005), 4130-4132.

[8] S. Poturovic, D. Lu, M. J. Heeg, et al. Synthesis and structural characterization of heavier group 1 methyl tetrazolate complexes: New bridging coordination modes of the tetrazolate ligand, Polyhedron, 27(2008), 3280-3286.

[9] X. S. Wang, Y. Z. Tang, X. F. Huang, et al. Syntheses, crystal structures, and luminescent properties of three novel zinc coordination polymers with tetrazolyl ligands, Inorg. Chem., 44(2005), $5278-5285$.

[10] R. X. Yao, Y. L. Qin, F. Ji, et al. Triangle, square and delta-chain based cobalt tetrazolate magnets, Dalton T., 42(2013), 6611-6618.

[11] X. He, C. D. Wu, M. X. Li, et al. Synthesis, structure and properties of two new 3D frameworks with primitive cubic topology, Inorg. Chem. Commun., 11(2008), 1378-1381.

[12] Z. X. Chen, H. M. Xiao. Theoretical Study on Tetrazole and Its Derivatives, Acta Chim. Sinica, 56(1998), 535-537.

[13] C. S. Zhou, G. Fan, S. P. Chen, et al. Synthesis, Crystal structure and Characterization of a Novel Energetic Complex [Mn (BTA)(phen) $\left.{ }_{2} \cdot 5 \mathrm{H}_{2} \mathrm{O}\right] \mathrm{n}$, Acta Chim. Sinica, 66(2008), 1776-1780.

[14] C. Y. Geng, M. C. Hu, S. N. Li, et al. Preparation, Crystal Structure and Thermodynamic Properties of Cs(ATZ), Acta Chim. Sinica, 63(2005), 1974-1978.

[15] J. Shang, J. G. Zhang, Y. CUI, et al. Synthesis, Crystal structure and Properties of an Energetic Compound $\left[\mathrm{Zn}(1,5 \text {-diaminotetrazole })_{6}\right]\left(\mathrm{ClO}_{4}\right)_{2}$, Acta Chim. Sinica, 68(2010), 233-238.

[16] W. Li, Y. H. Ren, F. Q. Zhao, et al. Effects of Lead Complex-Based BTATz on Thermal Behaviors, Non-Isothermal Reaction Kinetics and Combustion Properties of DB/RDX-CMDB Propellants, Acta Phys-Chim. Sin., 29(2013), 2087-2094.

[17] Q. Wang, H. X. Ma, J. Z. Li, et al. Theoretical Studies on the Relationships between Molecular Structure or Thermodecomposition Parameters and Impact Sensitivity of Azotetrazolate Nonmetallic Salts, Acta Chim. Sinica, 70(2012), 629-634.

[18] X. Wang, J. Liu, D. Wang, et al. Synthesis and Characterization of Sodium 5-Chlorotetrazolate Dihydrate by Chlorination of 1H-Tetrazole, Z. Anorg. Allg. Chem., 641(2014), 631-635. 